\title{
Dietas com diferentes densidades nutricionais para frangos de corte mantidos em ambientes com e sem nebulização
}

\author{
Diets with different nutrient densities for broilers kept in environments with and without \\ fogging
}

\section{CARVALHO FILHO, Domingos Urquiza de ${ }^{1 *}$; FIGUEIREDO, Agustinho Valente de ${ }^{2}$; LIMA, Daniela Cristina Pereira ${ }^{1}$; SILVA, Melina da Conceição Macêdo da ${ }^{1}$; COSTA, Elvania Maria da Silva ${ }^{1}$; LIMA, Vânia Batista de Sousa ${ }^{1}$}

\footnotetext{
${ }^{1}$ Universidade Federal do Piauí, Centro de Ciências Agrárias, Programa de Pós-Graduação em Ciência Animal, Teresina, Piauí, Brasil.

${ }^{2}$ Universidade Federal do Piauí, Centro de Ciências Agrárias, Departamento de Zootecnia, Teresina, Piauí, Brasil

*Endereço para correspondência: urquizafilho@hotmail.com
}

\section{RESUMO}

Esta pesquisa foi desenvolvida para avaliar o efeito da densidade nutricional da dieta, sobre as variáveis de desempenho de frangos de corte, mantidos em ambientes com ventilação, associado ou não a nebulização, nos períodos de oito a 21 e de oito a 41 dias de idade, bem como, avaliar o rendimento de carcaça, cortes e gordura abdominal aos 41 dias de idade das aves. $\mathrm{O}$ delineamento utilizado foi inteiramente ao acaso, em esquema fatorial, com três tratamentos e seis repetições, em dois ambientes, sendo 20 aves por unidade experimental. Os tratamentos consistiram de três dietas com diferentes densidades nutricionais: controle; média e alta densidade. O sistema de resfriamento evaporativo com ventilação associado à nebulização, em condição de temperatura e umidade relativa do ar elevadas, proporciona aumento no consumo de ração, mas piora a conversão alimentar dos frangos de corte na fase inicial. Para o período de oito a 41 dias, o ambiente com ventilação associada à nebulização proporciona às aves aumento no consumo de ração e no ganho de peso, sem afetar a conversão alimentar. A dieta de alta de densidade nutricional, na fase de oito a 21 dias, reduz o consumo de ração e melhora conversão alimentar em relação à dieta controle. Para o período de oito a 41 dias, a dieta de média densidade proporciona maior ganho de peso e melhor conversão alimentar em relação ao controle. As diferentes densidades nutricionais não afetam o rendimento de carcaça, dos principais cortes e gordura abdominal aos 41 dias de idade.

Palavras-chave: avicultura, calor, carcaça, desempenho, energia

\section{SUMMARY}

This study was designed to evaluate effect of nutrient density of diet, on performance variables of broilers, kept in environments with ventilation, with or without fogging, in periods of eight to 21 and eight to 41 days of age, as well as, to evaluate carcass yield, abdominal fat and cuts at 41 days of age birds. The experimental design was completely randomized in a factorial design, with three treatments and six replications, in two environments, with 20 birds per experimental unit. Treatments consisted of three diets with different nutrient densities: control; medium and high density. The evaporative cooling system with ventilation associated nebulization, on condition of temperature and relative humidity elevated air, provides an increase in feed intake, but worse feed conversion of broilers in the initial phase. For eight to 41 days, environment with ventilation associated fogging provides birds increase in feed intake and weight gain, without affecting feed conversion. Diet high nutrient density, phase eight to 21 days, reduces feed intake and improved feed conversion compared to the 
control diet. For eight to 41 days, diet of medium density provides greater weight gain and better feed conversion compared to control. Different nutritional levels do not affect carcass yield, abdominal fat and major cuts at 41 days of age.

Keywords: carcass, energy, heat, performance, poultry

\section{INTRODUÇÃO}

Inúmeras pesquisas são realizadas com frangos de corte sendo a maioria conduzida com animais mantidos em ambiente termoneutro ou em câmara climática, relevando o estresse cíclico provocado pelo calor em condições naturais de regiões quentes ou com grandes variações climáticas, que pode interferir na expressão do potencial genético, na eficiência de utilização dos nutrientes e no aspecto sanitário das aves.

Estabelecer o nível ótimo de densidade nutricional ou a relação energia metabolizável: proteína bruta (EM:PB) para melhorar $\mathrm{o}$ desempenho $\mathrm{e} \mathrm{o}$ rendimento de carcaça das aves, é um desafio, sobretudo nos períodos mais quentes do ano, em que ocorre redução do consumo de ração e consequentemente, dos nutrientes. A opção de aumentar a densidade nutricional da dieta, para garantir a ingestão adequada de nutrientes pelas aves, pode elevar e incremento calórico, em função do aumento da proteína bruta na ração (GONZALEZ-ESQUERRA \& LESSON, 2005; AFTAB et al., 2006; FARIA FILHO et al., 2006; SIQUEIRA et al., 2007).

Por outro lado, a redução da proteína bruta abaixo das recomendações das tabelas nutricionais, mesmo com suplementação de aminoácidos industriais, prejudica o desempenho dos frangos de corte sob estresse por calor
(DEAN et al., 2006; FARIA FILHO et al., 2006; FARIA FILHO et al., 2007; LAGANÁ et al., 2007; ZAMAN et al., 2008; OLIVEIRA NETO \& OLIVEIRA, 2009). Segundo Swennen et al. (2004) e Swennen et al. (2006), a ausência dos efeitos benéficos esperados no desempenho dessas aves pode indicar que a produção de calor corporal nestes animais, ao contrário do que ocorre nos mamíferos adultos, não é induzida pela concentração de proteína bruta da dieta. Além disso, os genótipos utilizados nos estudos para avaliar o efeito da redução do nível de proteína bruta da dieta dos frangos de corte, sob estresse por calor, podem justificar as divergências entre os resultados encontrados na literatura (OLIVEIRA et al., 2010).

Esta pesquisa foi realizada com o objetivo de avaliar o efeito das diferentes densidades nutricionais das dietas, sobre as variáveis de desempenho e viabilidade da criação de frangos de corte, mantidos em ambientes com e sem nebulização, nos períodos de oito a 21 e de oito a 41 dias de idade, bem como avaliar o rendimento de carcaça, dos principais cortes e gordura abdominal aos 41 dias de idade das aves.

\section{MATERIAL E MÉTODOS}

A pesquisa foi realizada no Setor de Avicultura do Departamento de Zootecnia do Centro de Ciências Agrárias (CCA) da Universidade Federal do Piauí (UFPI). O experimento foi instalado em dois galpões de alvenaria coberto de telhas de cerâmica e piso cimentado, ambos com ventiladores e cortinas nas laterais para melhor controle da temperatura e correntes de ar. Um dos galpões continha sistema de nebulização. Estes equipamentos foram acionados somente 
Tabela 2. Composições percentuais e calculadas das dietas experimentais utilizadas no período de 22 a 33 e de 34 a 41 dias de idade

\begin{tabular}{|c|c|c|c|c|c|c|c|}
\hline \multirow{3}{*}{ Ingredientes $(\%)$} & & \multicolumn{4}{|c|}{22 a 33 dias } & \multicolumn{2}{|c|}{34 a 41 dias } \\
\hline & & Controle & $\begin{array}{c}\text { Média } \\
\text { densidade }\end{array}$ & $\begin{array}{c}\text { Alta } \\
\text { densidade }\end{array}$ & Controle & Média densidade & Alta densidade \\
\hline & EM:PB & 163,76 & 165,80 & 172,63 & 178,67 & 182,68 & 185,00 \\
\hline Milho & & 69,79 & 66,77 & 66,82 & 73,06 & 69,47 & 68,86 \\
\hline Farelo de soja & & 20,50 & 13,80 & 7,30 & 17,10 & 8,90 & 4,40 \\
\hline Soja extrusada integral & & 4,70 & 14,20 & 19,50 & 5,40 & 17,10 & 21,40 \\
\hline Farinha de carne e ossos & & 2,90 & 2,80 & 4,20 & 2,40 & 2,40 & 3,40 \\
\hline Calcário & & 0,65 & 0,65 & 0,40 & 0,70 & 0,70 & 0,45 \\
\hline Sal & & 0,24 & 0,25 & 0,21 & 0,22 & 0,23 & 0,20 \\
\hline Bicarbonato de sódio & & 0,26 & 0,26 & 0,26 & 0,26 & 0,26 & 0,26 \\
\hline DL-Metionina (99\%) & & 0,21 & 0,33 & 0,34 & 0,19 & 0,22 & 0,29 \\
\hline L-Lisina $(78 \%)$ & & 0,28 & 0,38 & 0,42 & 0,29 & 0,28 & 0,34 \\
\hline L-Treonina $(98 \%)$ & & 0,04 & 0,13 & 0,11 & 0,05 & 0,11 & 0,07 \\
\hline Ronozyme ProAct ${ }^{1}$ & & 0,02 & 0,02 & 0,02 & 0,02 & 0,02 & 0,02 \\
\hline Ronozyme NP (CT) $150 \mathrm{~g}$ & & 0,01 & 0,01 & 0,02 & 0,01 & 0,01 & 0,01 \\
\hline Suplemento vitamínico e mineral ${ }^{2}$ & & 0,40 & 0,40 & 0,40 & 0,30 & 0,30 & 0,30 \\
\hline Total $(\mathrm{kg})$ & & 100,00 & 100,00 & 100,00 & 100,00 & 100,00 & 100,00 \\
\hline \multicolumn{8}{|l|}{ Composição calculada } \\
\hline Proteína bruta $(\%)$ & & 18,93 & 19,3 & 19,00 & 17,63 & 17,90 & 18,00 \\
\hline Energia metabolizável (Kcal/Kg) & & 3.100 & 3.200 & 3.280 & 3.150 & 3.270 & 3.330 \\
\hline Lisina digestiva $(\%)$ & & 1,03 & 1,12 & 1,10 & 0,96 & 0,97 & 0,98 \\
\hline Metionina + cistina digestiva $(\%)$ & & 0,74 & 0,86 & 0,85 & 0,69 & 0,72 & 0,77 \\
\hline Treonina digestiva $(\%)$ & & 0,67 & 0,76 & 0,72 & 0,63 & 0,70 & 0,64 \\
\hline Cálcio $(\%)$ & & 1,03 & 1,12 & 1,1 & 0,74 & 0,74 & 0,77 \\
\hline Fósforo disponível (\%) & & 0,74 & 0,86 & 0,85 & 0,44 & 0,45 & 0,51 \\
\hline Sódio $(\%)$ & & 0,20 & 0,20 & 0,19 & 0,19 & 0,19 & 0,18 \\
\hline
\end{tabular}

$\mathrm{EM}: \mathrm{PB}=$ relação energia metabolizável: proteína bruta.

${ }^{1}$ Protease para as fases de crescimento e abate; ${ }^{2}$ Composição premix: Ácido Fólico - 100mg, Antioxidante - 125mg, Cobre - 15.000mg, Coccidiostático - 25.000mg, Colina - 50.000mg, Ferro - 10.000mg, Iodo - 250mg, Manganês - 24.000mg, Metionina - 307.000mg, Niacina - 20.000mg, Pantotenato de cálcio - 2.000mg, Selênio - 50mg, Veículo QSP - 1.000g, Vitamina A - 300.000 UI/Kg, Vitamina B1 - 400g, Vitamina B12 - 4.000mcg, Vitamina B2 - 1.320mg, Vitamina D3 $100.000 \mathrm{UI} / \mathrm{Kg}$, Vitamina E - $4.000 \mathrm{UI} / \mathrm{Kg}$, Vitamina K - 98mg, Zinco - 20.000mg, promotor de crescimento - $10.000 \mathrm{mg}$. 
Cada galpão continha 18 boxes de 2,5 $\mathrm{m}^{2}$, e em cada boxe foram distribuídos 20 pintos da linhagem Ross, com oito dias de idade, sendo 10 machos e 10 fêmeas, num total de 360 aves por galpão. Todas as aves receberam água limpa, ração à vontade, e sistema de aquecimento nos dez primeiros dias de vida. O programa de luz foi contínuo, durante as 24 horas do dia, sendo das $6 \mathrm{~h} 30 \mathrm{~min}$ às $17 \mathrm{~h} 30 \mathrm{~min}$, iluminação natural, e o restante, luz artificial. O monitoramento da temperatura $\mathrm{e}$ umidade relativa do ar dos galpões foi feito por termohigrômetros de máxima e mínima, colocados à altura intermediária em relação aos boxes. As leituras foram realizadas diariamente, às $8 \mathrm{~h} 30 \mathrm{~min} \mathrm{e}$ $15 \mathrm{~h} 30 \mathrm{~min}$, e seus valores médios estão apresentados na tabela 3. As médias máximas de umidade relativa do ar em torno de $90 \%$, em ambos os galpões, foram em decorrência de chuvas no período, pois os nebulizadores foram acionados apenas quando necessários e após o $12^{\circ}$ dia de vida das aves.

Tabela 3. Valores médios de temperatura e umidade relativa do ar, obtidos no período experimental

\begin{tabular}{ccccccccc}
\hline \multirow{2}{*}{$\begin{array}{c}\text { Período } \\
\text { (dias) }\end{array}$} & \multicolumn{2}{c}{$\begin{array}{c}\text { Galpão com ventilação e sem nebulização } \\
\text { Temperatura }\end{array}$} & \multicolumn{2}{c}{$\begin{array}{c}\text { Umidade relativa } \\
\text { do ar }(\%)\end{array}$} & \multicolumn{2}{c}{ Temperatura $\left({ }^{\circ} \mathrm{C}\right)$} & \multicolumn{2}{c}{$\begin{array}{c}\text { Umidade relativa } \\
\text { do ar }(\%)\end{array}$} \\
\cline { 2 - 8 } & Máxima & Mínima & Máxima & Mínima & Máxima & Mínima & Máxima & Mínima \\
\hline 8 a 21 & $33,5 \pm 0,3$ & $23,5 \pm 0,6$ & $93,0 \pm 1,5$ & $60,1 \pm 1,8$ & $32,7 \pm 0,1$ & $22,1 \pm 0,5$ & $92,1 \pm 3,6$ & $58,6 \pm 4,9$ \\
22 a 33 & $33,1 \pm 0,5$ & $22,4 \pm 0,9$ & $90,2 \pm 3,1$ & $42,1 \pm 8,6$ & $33,1 \pm 0,5$ & $22,0 \pm 1,1$ & $89,5 \pm 4,0$ & $42,6 \pm 13,8$ \\
34 a 41 & $33,5 \pm 0,1$ & $20,6 \pm 1,1$ & $92,8 \pm 0,8$ & $38,7 \pm 5,3$ & $32,6 \pm 0,3$ & $19,0 \pm 0,8$ & $88,0 \pm 5,0$ & $36,5 \pm 6,3$ \\
\hline
\end{tabular}

A viabilidade da criação, o consumo de ração, o ganho de peso e a conversão alimentar foram avaliados aos 21 e 41 dias de idade. Aos 41 dias, duas aves por boxe, escolhidas dentro do peso médio do boxe, totalizando 12 aves por tratamento, foram submetidas a jejum e dieta hídrica de oito horas, em seguida foram pesadas e abatidas para avaliar rendimento de carcaça, dos principais cortes e gordura abdominal. Os dados obtidos foram submetidos à análise de variância por meio do procedimento General Linear Model (GLM) do SAS Institute (2002), e no caso de diferença significativa, as médias foram comparadas pelo teste de Tukey, excetuando o rendimento de gordura abdominal, que se aplicou o StudentNewman-Keuls (SNK), ambos a 5\% de probabilidade.

\section{RESULTADOS E DISCUSSÃO}

Os valores de temperatura registrados no interior dos galpões observados na Tabela 3 caracterizam que, a partir da segunda semana de vida, a pesquisa foi desenvolvida em ambiente fora da zona de conforto térmico, causando aos frangos de corte, estresse cíclico por calor, visto que, nos dois galpões, as médias máximas de temperatura $\mathrm{e}$ umidade relativa do ar ultrapassam a zona de termoneutralidade, o que pode comprometer o desempenho das aves. De acordo com Faria Filho et al. (2006), a condição de conforto térmico é obtida, a partir da $2^{\mathrm{a}}$ semana de vida, em locais com temperaturas de 18 a $22-25^{\circ} \mathrm{C}$ e umidade relativa do ar de 50 a $70 \%$. Em ambiente termoneutro a taxa metabólica das aves é mínima, a homeotermia é 
mantida com menos gasto energético, e o calor proveniente do metabolismo é dissipado para o ambiente sem prejuízo no desempenho produtivo (OLIVEIRA et al., 2006a; OLIVEIRA et al.; 2006b; TEIXEIRA \& BAIÃO, 2012).
A Tabela 4 apresenta os dados do desempenho produtivo e da viabilidade da criação de frangos de corte no período de oito a 21 dias, alojados em galpões com ventilação, associados ou não a nebulização e submetidos a dietas de diferentes densidades nutricionais.

Tabela 4. Desempenho produtivo de frangos de corte no período de 8 a 21 dias de idade, alimentados com dietas contendo diferentes densidades nutricionais, mantidos em ambientes com ventilação positiva, associado ou não à nebulização

\begin{tabular}{|c|c|c|c|c|c|}
\hline Variáveis & & $\begin{array}{c}\text { CMDR } \\
(\mathrm{g})\end{array}$ & $\begin{array}{c}\text { GPMD } \\
(\mathrm{g})\end{array}$ & CA & $\mathrm{VC}(\%)$ \\
\hline Galpão com ventilação e nebulização & & $77,93^{\mathrm{a}}$ & $57,21^{\mathrm{a}}$ & $1,35^{\mathrm{a}}$ & $99,17^{\mathrm{a}}$ \\
\hline Galpão com ventilação e sem nebulização & & $76,00^{\mathrm{b}}$ & $57,36^{\mathrm{a}}$ & $1,32^{\mathrm{b}}$ & $99,44^{\mathrm{a}}$ \\
\hline \multicolumn{6}{|c|}{ EM:PB } \\
\hline Probabilidade da interação ambiente $\mathrm{x}$ dieta & - & 0,9262 & 0,1253 & 0,0803 & 0,4294 \\
\hline Dieta controle & 143,06 & $77,86^{\mathrm{a}}$ & $55,86^{\mathrm{b}}$ & $1,36^{\mathrm{a}}$ & $98,75^{\mathrm{a}}$ \\
\hline Dieta de média densidade nutricional & 144,81 & $78,07^{\mathrm{a}}$ & $58,64^{\mathrm{a}}$ & $1,33^{\mathrm{ab}}$ & $99,58^{\mathrm{a}}$ \\
\hline Dieta de alta densidade nutricional & 145,58 & $74,93^{\mathrm{b}}$ & $57,29^{\mathrm{ab}}$ & $1,31^{\mathrm{b}}$ & $99,58^{\mathrm{a}}$ \\
\hline Coeficiente de variação (\%) & & 3,14 & 3,29 & 2,31 & 1,80 \\
\hline
\end{tabular}

Médias na mesma coluna seguida da mesma letra não diferem entre si pelo teste de Tukey $(\mathrm{P}>0,05)$. $\mathrm{CMDR}=$ consumo médio diário de ração. GPMD = ganho de peso médio diário. $\mathrm{CA}=$ conversão alimentar. $\mathrm{VC}$ = viabilidade da criação. $\mathrm{EM}: \mathrm{PB}$ = relação energia metabolizável : proteína bruta.

O consumo médio diário de ração foi afetado pelo micro clima dos galpões $(\mathrm{P}<0,05)$, o menor consumo observado no galpão sem nebulização pode ter sido em decorrência da maior média de temperatura interna registrada neste ambiente $\left(28,5^{\circ} \mathrm{C}\right)$ em relação ao galpão com nebulização $\left(27,4^{\circ} \mathrm{C}\right)$. A influência negativa da temperatura elevada sobre a ingestão voluntária de alimentos em frangos de corte também foi observada por Oliveira Neto et al. (2000b); Pope \& Emmer (2002) e Shan et al. (2003). Oliveira et al. (2006b) relataram redução média de $2,2 \%$ no consumo de ração à cada grau centígrado acima da zona de conforto térmico, para frangos de corte no período de um a 49 dias de idade. A redução na ingestão de alimentos é uma alteração fisiológica das aves, em estresse por calor, para minimizar a produção de calor metabólico.

$\mathrm{O}$ ganho de peso médio diário e viabilidade da criação não diferiram $(\mathrm{P}>0,05)$ em função da climatização, entretanto, a melhor conversão alimentar $(\mathrm{P}<0,05)$ foi obtido no ambiente apenas com ventilação. Neste ambiente, a ventilação parece que foi eficiente na renovação do ar e na remoção do excesso de umidade do ar (provocado pelas chuvas do período) e da cama (proveniente da respiração e das excretas das aves), o que favoreceu a perda de calor por meios sensíveis e evaporativos nos momentos de temperatura e umidade elevadas, e minimizou a exigência de energia para manter os mecanismos de resfriamento corporal, com reflexo na melhoria da conversão alimentar. 
Não houve interação entre o ambiente e a dieta sobre as variáveis estudadas $(\mathrm{P}>0,05)$. A dieta de alta densidade $(E M: P B=145,58)$ provocou redução no consumo de ração e proporcionou às aves melhor conversão alimentar $(\mathrm{P}<0,05)$ em relação à dieta controle (EM:PB=143,06). A redução no consumo de ração na maior relação EM:PB, provavelmente foi causada pelo desequilíbrio na concentração de energia e proteína (aminoácidos) da dieta. Nascimento et al.(2004) obtiveram resultados semelhantes a esse trabalho para o consumo de ração, avaliando as relações EM:PB de 125,0; 136,9 e 151,5 , em frangos de corte de 8 a 21 dias, no entanto, a menor relação EM:PB $(125,0)$ foi a que proporcionou melhor conversão alimentar, o que não se confirma nessa pesquisa, onde a melhor conversão alimentar ocorreu na relação EM:PB mais elevada $(145,58)$, o que corrobora com Oliveira Neto et al. (2000a), os quais observaram redução linear na conversão alimentar, com o aumento da energia metabolizável em dietas isoprotéicas para frangos de 22 a 42 dias, e justificam a melhoria da conversão alimentar com a elevação dos níveis de energia metabolizável na dieta, pela maior eficiência na utilização da proteína e maior deposição de gordura na carcaça. A dieta de média densidade (EM:PB=144,81) proporcionou às aves maior ganho de peso $(\mathrm{P}<0,05)$ em relação à dieta controle, entretanto, não diferiu $(\mathrm{P}>0,05)$ da dieta de alta densidade nessa variável. As dietas não interferiram na viabilidade da criação $(\mathrm{P}>0,05)$.

Aves alojadas em galpão com nebulização obtiveram maior $(\mathrm{P}<0,05)$ consumo médio diário de ração e maior ganho de peso médio diário, em relação às aves alojadas em galpão sem nebulização, contudo, a conversão alimentar e a viabilidade da criação não diferiram $(\mathrm{P}>0,05)$ em função do ambiente (Tabela 5).

Tabela 5. Desempenho produtivo de frangos de corte no período de 8 a 41 dias de idade, alimentados com dietas contendo diferentes densidades nutricionais, mantidos em ambientes com ventilação positiva, associado ou não à nebulização

\begin{tabular}{|c|c|c|c|c|c|}
\hline Variáveis & & $\begin{array}{c}\text { CMDR } \\
(\mathrm{g})\end{array}$ & $\begin{array}{c}\text { GPMD } \\
(\mathrm{g})\end{array}$ & $\mathrm{CA}$ & $\begin{array}{l}\mathrm{VC} \\
(\%) \\
\end{array}$ \\
\hline Galpão com ventilação e nebulização & & $122,56^{\mathrm{a}}$ & $72,39^{\mathrm{a}}$ & $1,69^{\mathrm{a}}$ & $98,33^{\mathrm{a}}$ \\
\hline \multicolumn{2}{|l|}{ Galpão com ventilação e sem nebulização } & $118,83^{\mathrm{b}}$ & $68,67^{\mathrm{b}}$ & $1,73^{\mathrm{a}}$ & $98,89^{\mathrm{a}}$ \\
\hline & EM:PB & & & & \\
\hline \multicolumn{6}{|c|}{ Média de 8 a 41 dias } \\
\hline $\begin{array}{l}\text { Probabilidade da interação } \\
\text { ambiente x dieta }\end{array}$ & - & 0,4988 & 0,2067 & 0,4475 & 0,9250 \\
\hline Dieta Controle & 161,83 & $121,83^{\mathrm{a}}$ & $69,50^{\mathrm{b}}$ & $1,75^{\mathrm{a}}$ & $98,75^{\mathrm{a}}$ \\
\hline $\begin{array}{l}\text { Dieta de média densidade } \\
\text { nutricional }\end{array}$ & 164,43 & $122,50^{\mathrm{a}}$ & $72,42^{\mathrm{a}}$ & $1,69^{\mathrm{b}}$ & $97,92^{\mathrm{a}}$ \\
\hline $\begin{array}{l}\text { Dieta de alta densidade } \\
\text { nutricional }\end{array}$ & 167,74 & $117,75^{\mathrm{a}}$ & $69,67^{\mathrm{ab}}$ & $1,69^{\mathrm{b}}$ & $99,17^{\mathrm{a}}$ \\
\hline Coeficiente de variação (\%) & & 3,97 & 4,02 & 3,62 & 3,02 \\
\hline
\end{tabular}


O incremento no consumo de ração e no ganho de peso pode ser creditado à melhor sensação térmica do ambiente com nebulização, que favoreceu a dissipação de calor das aves e contribuiu para o aumento da deposição na carcaça. Aves em estresse por calor reduz a ingestão de alimento, na tentativa de minimizar a produção de calor metabólico, e parte da energia dietética ingerida é gasta no processo de dissipação do calor que, na ausência do estresse térmico, estaria disponível para a produção.

Não houve interação entre o ambiente e a dieta sobre as variáveis avaliadas no período de oito a 41 dias de idade das aves $(\mathrm{P}>0,05)$. As dietas com diferentes densidades nutricionais não interferiram $(\mathrm{P}>0,05)$ no consumo de ração $\mathrm{e}$ viabilidade da criação. Conquanto, a dieta de média densidade (EM:PB=164,43) proporcionou maior ganho de peso $\mathrm{e}$ melhor conversão alimentar em relação à dieta controle (EM:PB=161,83), e não diferiu $(\mathrm{P}>0,05)$ da dieta de alta densidade (EM:PB=167,74). A melhoria no ganho de peso e na conversão alimentar, com o aumento da energia metabolizável da dieta pode ser atribuída ao efeito extracalórico, que consiste no aumento da disponibilidade dos nutrientes dos ingredientes da ração, e ao efeito extrametabólico da gordura, que resulta em melhoria da eficiência energética pelo incremento da energia líquida da ração (SAKOMURA, 2004). Não houve interação entre o ambiente e a dieta $(\mathrm{P}>0,05)$ para o rendimento de carcaça, gordura abdominal, peito, coxa e sobrecoxa, aos 41 dias de idade das aves. $\mathrm{O}$ ambiente e a dieta, isoladamente, também não interferiram $(\mathrm{P}>0,05)$ no rendimento de carcaça, de gordura abdominal e dos cortes (Tabela 6).

Tabela 6. Rendimento de carcaça (RC), gordura abdominal (RGAB), peito (RP), coxa (RCX) e sobrecoxa (RSB) de frangos de corte com 41 dias de idade, alimentados com dietas contendo diferentes densidades nutricionais, mantidos em ambientes com ventilação positiva, associado ou não à nebulização

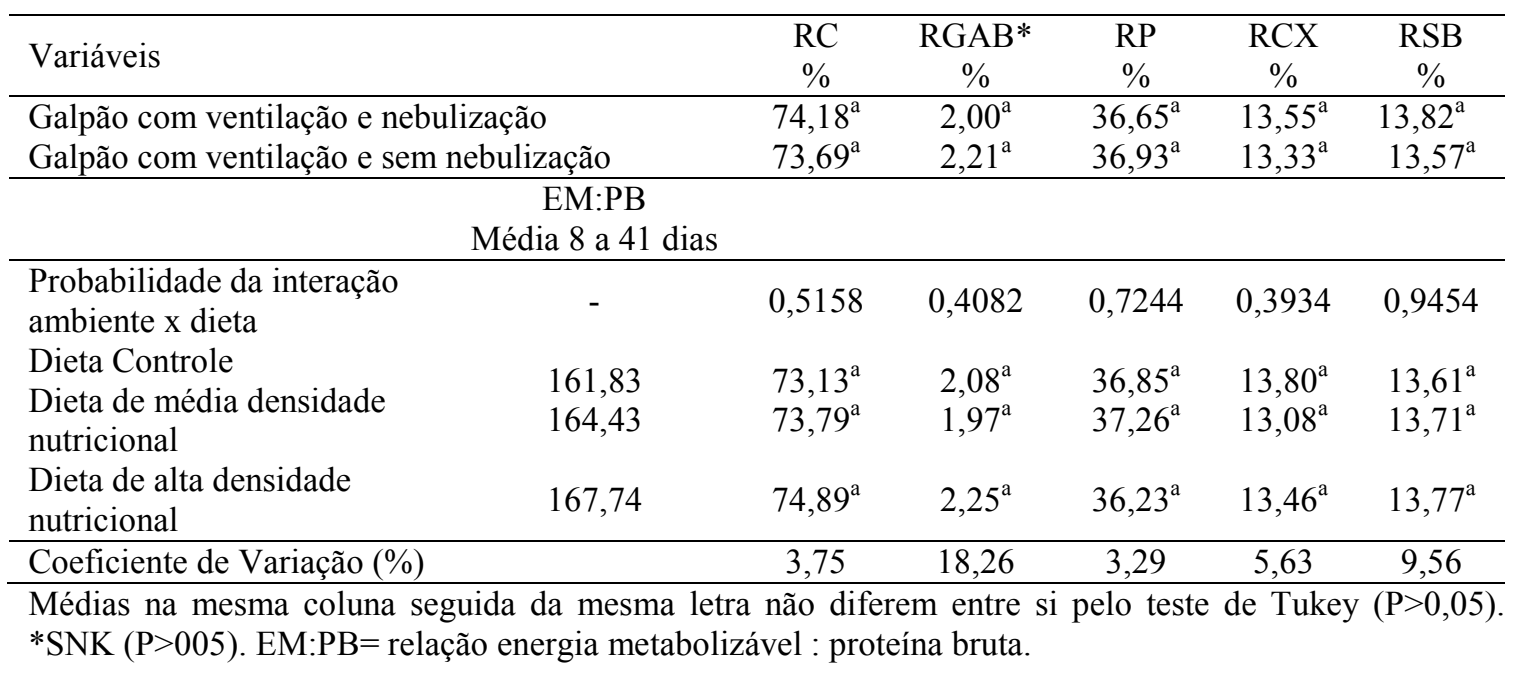

Similarmente, Oliveira Neto et al. (2000a) avaliaram dietas com 3000; $3075 ; 3150 ; 3225$ e $3300 \mathrm{kcal}$ de $\mathrm{EM} / \mathrm{kg}$ de ração, para frangos aos 42 dias de idade, e também não observaram diferenças no rendimento de carcaça, 
Rev. Bras. Saúde Prod. Anim., Salvador, v.15, n.2, p.297-307 abr./jun., 2014 http://www.rbspa.ufba.br ISSN 15199940

gordura abdominal, peito, coxa e sobrecoxa. Lana et al. (2000), trabalhando em ambientes com diferentes condições térmicas, também não observaram diferenças nos rendimentos de carcaça, peito, sobrecoxa, nem nos teores de extrato etéreo de frangos de corte aos 42 dias de idade, todavia, observaram maior rendimento de coxa em condição de maior desconforto térmico em comparação ao ambiente considerado termoneutro. Faria Filho et al. (2006), observaram que as temperaturas de 20; 25 e $32^{\circ} \mathrm{C}$ não alteraram os rendimentos de peito, asa e gordura abdominal aos 49 dias de idade, entretanto, os rendimentos de carcaça, coxa e sobrecoxa foram maiores em aves criadas em temperatura de $32^{\circ} \mathrm{C}$.

Constata-se que o sistema de resfriamento evaporativo com ventilação associada à nebulização, com períodos de temperatura e umidade relativa do ar elevadas, proporciona aumento no consumo de ração, mas piora a conversão alimentar dos frangos de corte de oito a 21 dias de idade. Para o período de oito a 41 dias, nessa mesma condição climática, esse sistema de resfriamento proporciona aumento no consumo de ração e no ganho de peso, em relação ao sistema sem nebulização.

Em condições de estresse cíclico por calor, a dieta com relação $\mathrm{EM}: \mathrm{PB}=145,58$, caracterizada neste trabalho como de alta densidade, proporciona, no período de oito a 21 dias, menor consumo de ração e melhor conversão em relação à dieta controle (EM:PB=143,06). Para o período total, a dieta de média densidade (EM:PB=164,43) proporciona maior ganho de peso e melhor conversão alimentar em relação ao controle $(\mathrm{EM}: \mathrm{PB}=161,83)$.

\section{REFERENCIAS}

AFTAB, U.; ASHRAF, M.; JIANG, Z. Low protein diets for broilers. Worlds

Poultry Science Journal, v.62, n.4, p.688-698, 2006.

DEAN, D.W.; BIDNER, T.D.;

SOUTHERN, L.L. Glycine supplementation of low protein, amino acid-supplemented diets supports equal performance of broiler chicks. Poultry

Science, v.85, n.2, p.288-296, 2006.

FARIA FILHO, D.E.; ROSA, P.S.; FIGUEIREDO, D.F.; DAHLKE, F.; MACARI, M.; FURLAN, R.L. Dietas de baixa proteína no desempenho de frangos criados em diferentes temperaturas. Pesquisa Agropecuária Brasileira, v.41, n.1, p.101-106, 2006.

FARIA FILHO, D.E.; CAMPOS, D.M.B.; TORRES, K.A.A.; VIEIRA, B.S.; ROSA, P.S.; VAZ, A.M. Protein levels for heat-exposed broilers: performance, nutrient digestibility, and protein and energy metabolism.

International Journal of Poultry

Science, v.6, n.3, p.187-194, 2007.

GONZALEZ-ESQUERRA, R.; LESSON, S. Effects of acute versuschronic heat stress on broiler response to dietary protein. Poultry Science, v.84, n.10, p.1562-1569, 2005.

LAGANÁ, C.; RIBEIRO, A.M.L.; KESSLER, A.M.; KRATZ, L.R.; CHILANTI, P.C. Effects of the reduction of dietary heat increment on the performance, carcass yield, and diet digestibility of broilers submitted to heat stress. Revista Brasileira de Ciência Avícola, v.9, n.1, p.45-51, 2007. 
Rev. Bras. Saúde Prod. Anim., Salvador, v.15, n.2, p.297-307 abr./jun., 2014 http://www.rbspa.ufba.br ISSN 15199940

LANA, G.R.Q.; ROSTAGNO, H.S.; ALBINO, L.F.T.; LANA, A.M.Q.

Efeito da temperatura ambiente $\mathrm{e}$ restrição alimentar sobre o desempenho e composição de corporal de frangos de corte. Revista Brasileira de Zootecnia, v.29, n.4, p.1117-1123, 2000.

NASCIMENTO, A.H.; SILVA, J.H.V.; ALBINO, L.F.T. ; RUNHO, R.C.; POZZA, P.C. Energia Metabolizável e Relação Energia: Proteína Bruta nas Fases Pré-Inicial e Inicial de Frangos de Corte. Revista Brasileira de Zootecnia, v.33, n.4, p.911-918, 2004.

OLIVEIRA NETO, A.R.; OLIVEIRA, R.F.M.; DONZELE, J.L.; ROSTAGNO, H.S.; FERREIRA, R.A.; CARMO, H.M.do. Níveis de energia metabolizável para frangos de corte no período de 22 a 42 dias de idade mantidos em ambiente termoneutro.

Revista Brasileria de Zootecnia, v.29, n.4, p.1132-1140, 2000a.

OLIVEIRA NETO, A.R.; OLIVEIRA, R.F.M.; DONZELE, J.L.; ROSTAGNO, H.S.; FERREIRA, R.A.; CARMO, H.M. do. Efeito da temperatura ambiente sobre o desempenho e características de carcaça de frangos de corte alimentados com dieta controlada e dois níveis de energia metabolizável.

Revista Brasileira de Zootecnia, v.29, n.1, p.183-190, 2000b.

OLIVEIRA, G.A.; OLIVEIRA, R.F.M.; DONZELE, J.L.; CECON, P.R.; VAZ, R.G.M.V.; ORLANDO, U.A.D. Efeito da temperatura ambiente sobre o desempenho e as características de carcaça de frangos de corte dos 22 aos 42 dias. Revista Brasileira de Zootecnia, v.35, n.4, p.1398-1405, 2006a.
OLIVEIRA, R.F.M.; DONZELE, J.L.; ABREU, M.L.T.; FERREIRA, R.A.; VAZ, R.G.M.V.; CELLA, P.S. Efeitos da temperatura e da umidade relativa sobre o desempenho e o rendimento de cortes nobres de frangos de corte de 1 a 49 dias de idade. Revista Brasileira de Zootecnia, v.35, n.3, p.797-803, 2006 b.

OLIVEIRA NETO, A.R.; OLIVEIRA, W.P. Aminoácidos para frangos de corte. Revista Brasileira de Zootecnia, v.38, p.205-208, 2009. Supl. especial.

OLIVEIRA, W.P.; OLIVEIRA, R.F.M.; DONZELE, J.L.; GOMES, P.C.;

MARTINS, M. dos S.; ASSIS, A.P. de. Redução do nível de proteína bruta em rações para frangos de corte em ambiente de estresse por calor. Revista Brasileira de Zootecnia, v.39, n.5, p.1092-1098, 2010.

POPE, T.; EMMER, J.L. Impacto of phase-feeding on the growth performance of broilers subjected to high environmental temperatures.

Poultry Science, v.81, n.4, p.504-511, 2002.

ROSTAGNO, H.S.; ALBINO, L.F.T.; DONZELE, J.L.; GOMES, P.C.; OLIVEIRA, R.F.; LOPES, D.C.; FERREIRA, A.S.; BARRETO, S.L.T.

Tabelas brasileiras para aves $\mathrm{e}$ suínos: composição de alimentos e exigências nutricionais. 2.ed. Viçosa, MG: UFV, 2005. 186p.

SAKOMURA, N.K.; LONGO, F.A.; RABELLO, C.B.; WATANABE, K.; PELÍCIA; K.; FREITAS, E.R. Efeito do nível de energia metabolizável da dieta no desempenho e metabolismo energético de frangos de corte. Revista Brasileira de Zootecnia, v.33, n.6, p.1758-1767, 2004. Supl. 1. 
SHAN, A.S.; STERLING, K.G.; PESTI, G.M.; BAKALLI, R.I.; DRIVER, J.P.; TEJEDOR, A.A. The influence of temperature on the threonine and tryptophan requirements of young broiler chicks. Poultry Science, v.82, n.7, p.1154-1162, 2003.

SIQUEIRA, J.C.; OLIVEIRA, R.F.M.; DONZELE, J.L.; CECON, P.R.;

BALBINO, E.M.; OLIVEIRA, W.P. Níveis de lisina digestível da ração e temperatura ambiente para frangos de corte em crescimento. Revista

Brasileira de Zootecnia, v.36, n.6, p.2054-2062, 2007.

\section{STATISTICAL ANALYSIS}

SYSTEMS. User's guide. Version 9.0. Cary, NC, USA: SAS Institute Inc., 2002.

SWENNEN, Q.; JANSSENS, G.P.J.; DECUYPERE, E.; BUYSE, J. Effect of substitution between fat and protein on food intake and its regulatory mechanisms in broiler chickens: Energy and protein metabolism and dietinduced thermogenesis. Poultry Science, v.83, n.12, p.1997-2004, 2004.
SWENNEN, Q.; JANSSENS, G.P.J.; COLLIN, A.; Le BIHAN-DUVAL,E.; VERBEKE, K.; DECUYPERE, E.; BUYSE, J. Diet-induced thermogenesis and glucose oxidation in broiler chickens: influence of genotype and diet composition. Poultry Science, v.85, n.4, p.731-742, 2006.

TEIXEIRA, M.P.F.; BAIÃO, N.C. Efeito do ambiente térmico sobre a exigência aminoacídica de aves.

Revista Eletrônica Nutritime, v.9, n.1, p.1693-1703, 2012.

ZAMAN, Q.U.; MUSHTAQ, T.; NAWAZ, H.; MIRZA, M.A.; MAHMOOD, S.; AHMAD, T.; BABAR, M.E.; MUSHTAQ, M.M.H. Effect of varying dietary energy and protein on broiler performance in hot climate. Animal Feed Science and Technology, v.146, n.3-4, p.302-312, 2008.

Data de recebimento: 13/06/2013

Data de aprovação: 02/06/2014 